\section{Carotenoid intake and asthma prevalence in Thai children}

\author{
Sanguansak Rerksuppaphol,1 \\ Lakkana Rerksuppaphol2 \\ 1Department of Pediatrics and \\ 2Department of Preventive Medicine, \\ Faculty of Medicine, Srinakharinwirot \\ University, Thailand
}

\section{Abstract}

Several antioxidant nutrients have been described to inversely correlate with asthma. In order to quantify the intake of these substances, it is possible to measure skin levels by Raman spectroscopy, a novel non-invasive technique that can also be used in children. This cross-sectional school-based study involved 423 children from a rural area of Thailand. Asthmatic children were diagnosed according to a Health Interview for Asthma Control questionnaire. Skin carotenoid levels were measured with Raman spectroscopy. Demographic data were obtained by directly interviewing children and their parents, whereas anthropometric parameters were measured by trained staff. Intake of carotenoids, vitamin $\mathrm{A}$ and $\mathrm{C}$ were evaluated by a food frequency questionnaire. Overall incidence of asthma in Thai schoolchildren (aged $3.5-17.8$ years) was $17.3 \%$. There was no significant difference in dietary intake of carotenoids and vitamin $\mathrm{A}$ and $\mathrm{C}$, and skin carotenoid level between asthmatic and nonasthmatic children. Skin carotenoid level significantly correlated with all carotenoids and vitamin $\mathrm{A}$ intake $(\mathrm{P}<0.05)$. Carotenoids and vitamin $\mathrm{A}$ and $\mathrm{C}$ intakes, and skin carotenoid levels were not associated with the risk of asthma in Thai children. Skin carotenoids correlated with all carotenoids and vitamin A intake in mild to moderate degrees. Raman spectroscopy was confirmed to be a useful tool to determine antioxidant skin levels.

\section{Introduction}

The prevalence of asthma is a phenomenon which is dramatically increasing worldwide, especially in children under 18 years of age. 1,2 There is some evidence to demonstrate a possible correlation between asthma and diet. ${ }^{3}$ Several studies have widened our understanding of the role of nutrients in the cause, progression and prevention of asthma; a suboptimal intake of vitamin A, C and $E$ and other antioxidant nutrients seems to enhance asth- matic inflammation and contributes to bronchial hyper-reactivity. ${ }^{4}$ In particular, consumption of fruit seems to have a protective role versus asthma in children. ${ }^{5}$ These data are also supported by some evidence from animal studies; supplementation of antioxidants in diet contributes to a decrease in respiratory diseases. ${ }^{6}$ However, the results in human patients are difficult to interpret due to the differences in setting and demographics of the study population. ${ }^{7,8}$ Antioxidants may be useful, but additional studies on the association between antioxidants and asthma are to be encouraged. ${ }^{9}$ The majority of studies quantify antioxidants in relation to the amount of food intake rather than direct monitoring, 6,10 whereas there are few studies describing a direct measurement of antioxidant activity from blood or tissue, especially in children. Furthermore, nutritional assessment in children is not considered to be an accurate method to determine the levels of antioxidants. ${ }^{11,12}$ Raman spectroscopy is a specific form of vibrational spectroscopy for the detection of skin carotenoids. It has been reported to be highly sensitive, specific and precise in measuring skin carotenoid level because carotenoids can be excited by overlapping light wavelength of visible absorption bands and produce a strong resonance Raman scattering response. 13,14 The results are correlated with direct measurement of serum, ${ }^{15}$ and this noninvasive method may be successfully used in children. To our knowledge, there has been no study of skin carotenoid level and its correlation with asthmatic patients in Thai children. The primary aim of the study is, therefore, to assess the risks of asthma prevalence in correspondence to dietary carotenoid intake. A secondary aim is to correlate skin carotenoid level and dietary carotenoid intake by non-invasive Raman spectroscopy.

\section{Materials and Methods}

A cross-sectional school-based study was conducted in schoolchildren in one school of the Ongkaluck district, a rural region in central Thailand, during November and December 2010. Four hundred and twenty-three $(n=423)$ children were enrolled in the study, after obtaining approval and informed consent from parents and from children. The study was approved by the ethics committee of the Faculty of Medicine of Srinakharinwirot University.

Possible subjects of the study were considered to be all healthy children who voluntarily decided to participate and who had their parents' permission. Children with a known history of chronic diseases, such as diabetes mellitus, malignancy, chronic renal diseases, con-
Correspondence: Sanguansak Rerksuppaphol, Department of Paediatrics, Faculty of Medicine, Srinakhariwirot University, 62 Mo 7, RangsitNakorn Nayok Rd., NakornNayok, 26120 Thailand.

Tel. +66.817.231.766, Fax: +66.3739.5275

E-mail: sanguansak_r@hotmail.com

Key words: asthma, children, antioxidants, diet, Raman spectroscopy.

Acknowledgments: the present study was supported by grants from the Faculty of Medicine, Srinakharinwirot University, Thailand. We also thank Sala Elisa, PhD for editing the manuscript.

Contribution: SR designed methods and experiments, carried out the experiment, analyzed the data, interpreted the results and wrote the paper. LR co-designed the experiment, and co-worked on associated data collection and their interpretation.

Conflict of interest: the present study was supported by grants from Faculty of Medicine, Srinakharinwirot University, Thailand.

Received for publication: 6 September 2011. Revision received: 18 January 2012. Accepted for publication: 5 February 2012.

This work is licensed under a Creative Commons Attribution NonCommercial 3.0 License (CC BYNC 3.0).

(C) Copyright S. Rerksuppapho and L. Rerksuppaphol, 2012

Licensee PAGEPress srl, Italy

Pediatric Reports 2012; 4:e12

doi:10.4081/pr.2012.e12

genital heart diseases, and chronic liver diseases were excluded. Children who had skin lesions at the area of measurement of skin carotenoids were also excluded.

Trained staff collected demographic data by interviewing children and their parents. In particular, we used the National Health Interview Survey for Asthma Control (sample core: children) ${ }^{16}$ to classify asthmatic children. According to this, a child was considered asthmatic when a doctor or other health professional had diagnosed asthma in the previous twelve months. In this study, the questionnaire had been translated into Thai and parents of the children or their guardians were then asked to fill it in. Furthermore, we measured body weight and height in order to calculate the body mass index: weight was measured to the nearest $0.1 \mathrm{~kg}$ using an electronic scale while height was measured at the level of the tape to the nearest $0.1 \mathrm{~cm}$. The body mass index was calculated as the ratio between weight/ (height) ${ }^{2}\left[\mathrm{~kg} / \mathrm{m}^{2}\right]$. All measurements were taken by trained staff.

Food frequency records were obtained for a 
week. We then calculated the total intake of vitamin A, C and carotenoid. Each nutritional intake was calculated from food frequency records based on the USDA National Nutrient Database for standard. Therefore, skin carotenoid levels were measured by Raman spectroscopy (Biophotonic Scanner, Pharmanex, USA) on the palm of the right hand. The skin carotenoid score (SCS) was determined as previously described. 17 In summary, children were instructed to place the palm of their right hand in front of the scanner's low-energy blue light laser for $3 \mathrm{~min}$. Upon completion, the skin carotenoid score was reported on a computer screen.

Data were descriptively presented as mean and standard deviation, unless otherwise specified. The normality distributions of continuous variables were calculated with the KolmogorovSminov test. Differences in the normal distributed continuous variables between asthmatic and non-asthmatic children were tested by Student's t-test, whereas non-normal distributed variables were $\log$ transformed before being tested, again by Student's t-test. Differences of categorical variables between the 2 groups were tested by $\chi^{2}$ test. Correlations between skin carotenoid level and carotenoid (including vitamin A) intake were measured by Pearson's correlation test. Binary logistical regression analysis was used to measure the risk effects of various variables on asthma prevalence. Multicollinearity was identified among various carotenoid and vitamin A intakes; therefore, alpha carotenoid intake was used as representative of carotenoid intake in the logistical model. Statistical analysis was performed with SPSS (version 11.0, SPSS, Chicago, IL, USA) using intention-to-treat analysis. $\mathrm{P}<0.05$ was considered statistically significant.

\section{Results}

Four hundred and twenty-three children aged from 3.5 years to 17.8 years were included in the study after obtaining written informed consent. Seventy-three children (17.3\%) had been diagnosed with asthma. Of these children, 30 (41.1\%) had active asthma, $15(20.5 \%)$ were admitted to hospital due to asthma attack, and 28 (38.4\%) had time off school due to asthma attacks. Demographic data collected in the interview or at medical examination did not describe any significant difference between asthmatic children and control group in terms of sex, weight and BMI

Table 1. Demographic data of asthmatic children and control group.

\begin{tabular}{lccc} 
& $\begin{array}{c}\text { Children with asthma } \\
(\mathbf{n}=73)\end{array}$ & $\begin{array}{c}\text { Children with no asthma } \\
(\mathbf{n}=350)\end{array}$ & $\mathbf{P}$ \\
Boy (\%) & $40(54.8)$ & $185(52.9)$ & 0.79 \\
Age (year) & $9.2(3.4)$ & $10.3(3.2)$ & 0.01 \\
\hline Weight $(\mathrm{kg})$ & $31.8(14.5)$ & $34.4(14.4)$ & 0.09 \\
Height $(\mathrm{cm})$ & $129.7(19.0)$ & $135.3(18.2)$ & 0.02 \\
\hline BMI $\left(\mathrm{kg} / \mathrm{m}^{2}\right)$ & $17.9(4.0)$ & $18.0(3.9)$ & 0.69 \\
Smoking (\%) & $6(8.2)$ & $31(8.9)$ & 1.0 \\
\hline Smoker in family (n) & $23(31.5)$ & $129(36.9)$ & 0.42 \\
First child of family (\%) & $20(27.4)$ & $160(45.7)$ & $<0.01$ \\
\hline Second or last child & $53(72.6)$ & $190(54.3)$ & $<0.01$ \\
Asthma in family (\%) & $21(28.8)$ & $39(11.1)$ & $<0.01$ \\
\hline
\end{tabular}

Table 2. Dietary carotenoids, vitamin A and C intake. and skin carotenoid level in asthmatic children and control group.

\begin{tabular}{lccc} 
& $\begin{array}{c}\text { Children with asthma } \\
(\mathrm{n}=73)\end{array}$ & $\begin{array}{c}\text { Children with no asthma } \\
(\mathrm{n}=350)\end{array}$ & $\mathrm{P}$ \\
& $904.2(681.6)$ & $1,159.6(1,120.7)$ & 0.65 \\
$\alpha$-carotene intake $(\mu \mathrm{g} / \mathrm{wk})$ & $5,232.3(3524.5)$ & $5189.5(4,928.0)$ & 0.60 \\
$\beta$-carotene intake $(\mu \mathrm{g} / \mathrm{wk})$ & $1,028.4(816.9)$ & $1,045.6(877.3)$ & 0.39 \\
\hline$\beta$-cryptoxanthin intake $(\mu \mathrm{g} / \mathrm{wk})$ & $4,417.1(3,370.0)$ & $4,951.2(4,286.2)$ & 0.76 \\
\hline Lycopene intake $(\mu \mathrm{g} / \mathrm{wk})$ & $6,077.7(4,211.5)$ & $6,098.7(4,875.4)$ & 0.54 \\
\hline Lutein and zeaxanthin intake $(\mu \mathrm{g} / \mathrm{wk})$ & $17,950.4(8,444.6)$ & $358.8(11,265.2)$ & 0.93 \\
Vitamin A intake $(\mathrm{IU} / \mathrm{wk})$ & $406.5(310.6)$ & $12,529.6(4,817.0)$ & 0.33 \\
Vitamin C intake $(\mathrm{mg} / \mathrm{wk})$ & $12,295.6(3,872.8)$ & & 0.95 \\
\hline Skin carotenoid level $($ Raman intensity)
\end{tabular}

Data were reported as mean and standard deviation.

Table 3. Correlation among skin carotenoids level and carotenoid intake.

\begin{tabular}{|c|c|c|c|c|c|c|c|c|}
\hline & & $\begin{array}{c}\text { Skin } \\
\text { carotenoid } \\
\text { level }^{*}\end{array}$ & $\begin{array}{l}\alpha \text {-carotene } \\
\text { (mcg) }\end{array}$ & $\begin{array}{c}\beta \text {-carotene } \\
\text { (meg) }\end{array}$ & $\begin{array}{c}\beta \text {-cryptox } \\
\text { (mcg) }\end{array}$ & $\begin{array}{l}\text { Lycopene } \\
\text { (mcg) }\end{array}$ & $\begin{array}{l}\text { Lutein } \\
\text { zeaxantin } \\
\text { (mcg) }\end{array}$ & $\begin{array}{l}\text { Vitamin A } \\
\text { (IU) }\end{array}$ \\
\hline Skin carotenoid level ${ }^{*}$ & $\begin{array}{l}\text { Pearson's correlation } \\
\text { Sig. (two-tailed) }\end{array}$ & 1 & $\begin{array}{c}0.355^{* *} \\
0.000\end{array}$ & $\begin{array}{c}0.347^{* *} \\
0.000\end{array}$ & $\begin{array}{c}0.418^{* *} \\
0.000\end{array}$ & $\begin{array}{c}0.287^{* *} \\
0.000\end{array}$ & $\begin{array}{c}0.197^{* *} \\
0.000\end{array}$ & $\begin{array}{c}0.349^{* *} \\
0.000\end{array}$ \\
\hline$\alpha$-carotene (mcg) & $\begin{array}{l}\text { Pearson's correlation } \\
\text { Sig. (two-tailed) }\end{array}$ & $\begin{array}{c}0.355^{* *} \\
0.000\end{array}$ & 1 & $\begin{array}{c}0.795^{* *} \\
0.000\end{array}$ & $\begin{array}{c}0.568^{* *} \\
0.000\end{array}$ & $\begin{array}{c}0.404^{* *} \\
0.000\end{array}$ & $\begin{array}{c}0.305^{* *} \\
0.000\end{array}$ & $\begin{array}{c}0.741^{* *} \\
0.000\end{array}$ \\
\hline$\beta$-carotene (mcg) & $\begin{array}{l}\text { Pearson's correlation } \\
\text { Sig. (two-tailed) }\end{array}$ & $\begin{array}{c}0.347^{* *} \\
0.000\end{array}$ & $\begin{array}{c}0.795^{* *} \\
0.000\end{array}$ & 1 & $\begin{array}{c}0.727^{* *} \\
0.000\end{array}$ & $\begin{array}{l}0.621^{* *} \\
0.000\end{array}$ & $\begin{array}{c}0.689^{* *} \\
0.000\end{array}$ & $\begin{array}{c}0.931^{* *} \\
0.000\end{array}$ \\
\hline$\beta$-cryptoxanthin (mcg) & $\begin{array}{l}\text { Pearson's correlation } \\
\text { Sig. (two-tailed) }\end{array}$ & $\begin{array}{c}0.418^{* *} \\
0.000\end{array}$ & $\begin{array}{c}0.568^{* *} \\
0.000\end{array}$ & $\begin{array}{c}0.727^{* *} \\
0.000\end{array}$ & 1 & $\begin{array}{c}0.546^{* *} \\
0.000\end{array}$ & $\begin{array}{c}0.572^{* *} \\
0.000\end{array}$ & $\begin{array}{c}0.764^{* *} \\
0.000\end{array}$ \\
\hline Lycopene (mcg) & $\begin{array}{l}\text { Pearson's correlation } \\
\text { Sig. (two-tailed) }\end{array}$ & $\begin{array}{c}0.287^{* *} \\
0.000\end{array}$ & $\begin{array}{c}0.404^{* *} \\
0.000\end{array}$ & $\begin{array}{c}0.621^{* *} \\
0.000\end{array}$ & $\begin{array}{c}0.546^{* *} \\
0.000\end{array}$ & 1 & $\begin{array}{c}0.497^{* *} \\
0.000\end{array}$ & $\begin{array}{c}0.610^{* *} \\
0.000\end{array}$ \\
\hline $\begin{array}{l}\text { Lutein and zeaxanthin } \\
\text { (mcg) }\end{array}$ & $\begin{array}{l}\text { Pearson's correlation } \\
\text { Sig. (two-tailed) }\end{array}$ & $\begin{array}{c}0.197^{* *} \\
0.000\end{array}$ & $\begin{array}{c}0.305^{* *} \\
0.000\end{array}$ & $\begin{array}{c}0.689^{* *} \\
0.000\end{array}$ & $\begin{array}{c}0.572^{* *} \\
0.000\end{array}$ & $\begin{array}{c}0.497^{* *} \\
0.000\end{array}$ & 1 & $\begin{array}{c}0.815^{* *} \\
0.000\end{array}$ \\
\hline Vitamin A (IU) & $\begin{array}{l}\text { Pearson's correlation } \\
\text { Sig. (two-tailed) }\end{array}$ & $\begin{array}{c}0.349^{* *} \\
0.000\end{array}$ & $\begin{array}{c}0.741^{* *} \\
0.000\end{array}$ & $\begin{array}{c}0.931^{* *} \\
0.000\end{array}$ & $\begin{array}{c}0.764^{* *} \\
0.000\end{array}$ & $\begin{array}{l}0.610^{* *} \\
0.000\end{array}$ & $\begin{array}{l}0.815^{* *} \\
0.000\end{array}$ & 1 \\
\hline
\end{tabular}

"Skin carotenoid level determined by the mean of Raman spectroscopy. ${ }^{* *} \mathrm{P}=0.01$ statistical significance. 
(Table 1). By contrast, children with asthma were younger and shorter in height than healthy children. Children who smoked or who had smokers in the family were similarly distributed between the two groups $(\mathrm{P}=1.0$ and 0.42 , respectively) (Table 1$)$. Asthmatic children had significantly higher incidences of asthma in family member $(28.8 \%$ vs $11.1 \%$, $\mathrm{P}<0.01$, respectively). We then evaluated intake per week of antioxidants, carotenoids and vitamins, such as $\alpha$-carotene, $\beta$-carotene, $\beta$-cryptoxanthin, lycopene, lutein and zeaxanthin, vitamin A and C (Table 2). Distributions of skin carotenoid level, vitamin $\mathrm{A}$ and $\mathrm{C}$, and carotenoid intakes were not normalized with Kolmogorov-Smirnov test, therefore, the data were $\log$ transformed before being tested for difference. As reported in Table 2, there were no statistically different distributions between children with or without asthma diagnosis in terms of antioxidant intake and skin carotenoid level. Skin carotenoid levels determined by the mean of Raman spectroscopy correlated to the intake of all carotenoids and vitamin $A$, even if in mild (Luthein and zeaxanthin $0.2, \mathrm{P}<0.01)$ to moderate $(\beta$-cryptoxanthin $0.42, \mathrm{P}<0.01$ ) degree, as reported in Table 3. Moreover, among carotenoids, an inter-correlation was noted (Table 3). ). Finally, the risk of asthma negatively correlated with age (odds ratio [OR] 0.86; $95 \% \mathrm{CI} 0.78,0.95$ ) and positively correlated with family history (OR $3.63 ; 95 \%$ CI 1.89, 6.99).

\section{Discussion}

The prevalence of asthma has increased in Thai children within the last decades, indicating asthma is a possible national health concern. For instance, the International Study of Asthma and Allergy in Childhood (ISAAC) has reported that prevalence of current asthma is increasing from 1995 to 2001 among Thai children aged 6-7 and 13-14 years. ${ }^{18}$ The ISAAC study has been based on a survey carried out to identify asthmatic children. It is important to underline that there could have been linguistic problems which could have affected the reliability of the epidemiological results obtained with the survey, ${ }^{19}$ given that this ISAAC study used an English questionnaire translated into Thai. The present study is a cross-sectional study of schoolchildren in which asthmatic children have been classified by interviewing their parents or guardians. In general, the prevalence of asthma symptoms among children is difficult to determine with accuracy because few standards are available for diagnosis, and interview and survey are useful tools to examine the problem. Nevertheless, when wheezing or shortness of breath among infants reported by parents as assessed by questionnaire was compared to physicians' interviewing the parents themselves, higher prevalence rates were reported in interviews of the parents. ${ }^{20}$

This study focused on determining the role of carotenoid and vitamin $\mathrm{A}$ and $\mathrm{C}$ intake in asthmatic children. There is some evidence to indicate that dietary consumption of antioxidants seems to have a protective role against asthma. ${ }^{21}$ The main result of the present study is that no significant difference was identified in asthmatic and healthy Thai children in terms of carotenoid and vitamin $\mathrm{A}$ and $\mathrm{C}$ intake. Intake of carotenoids is low in Thai children because the weekly intake of fruit and vegetables, the main resource of these components, ${ }^{22}$ is quite limited. Raman spectroscopy has been shown to be useful in determining the skin carotenoid level that was correlated to carotenoid and vitamin A intake, indicating that Raman spectroscopy is a valuable tool to investigate and follow dietary carotenoids, as previously described. 17 Indeed, Raman spectroscopy directly correlates serum antioxidant levels to those of skin, ${ }^{23}$ is less invasive than serum measurements, and easier to use in children. The risks of asthma found in this study are negatively related to age, but positively related to the presence of asthma in the family, and are comparable to those described in literature. There is some evidence to indicate that the presence of other cases of asthma in the family increases the risk, ${ }^{24}$ demonstrating a genetic susceptibility in asthma predisposition. ${ }^{25}$ Environmental and genetic predispositions have to be added to developmental factors in the pathogenesis of childhood asthma, because childhood is a period of rapid growth of both the lungs and the immune system. ${ }^{26}$

\section{Conclusions}

The study found no significant difference in antioxidant intake in asthmatic and healthy Thai children. To evaluate and confirm the carotenoid and vitamin $A$ and $C$ intakes recorded in the food dietary reports, antioxidant skin levels were measured by Raman spectroscopy. This technique has been demonstrated to be useful and reliable in determining dietary antioxidant intakes. A correlation between diet and asthma has been extensively reported in literature, but further studies are necessary to improve prognosis and therapy, especially in childhood.

\section{References}

1. Corry DB, Kheradmand F. Toward a comprehensive understanding of allergic lung disease. Trans Am Clin Climatol Assoc 2009;120:33-48.

2. Patel SP, Jarvelin MR, Little MP. Systematic review of worldwide variations of the prevalence of wheezing symptoms in children. Environ Health 2008;7:57.

3. McKeever TM, Britton J. Diet and asthma. Am J Respir Crit Care Med 2004;170:725-9.

4. Greene LS. Asthma, oxidant stress, and diet. Nutrition 1999;15:899-907.

5. Romieu I, Trenga C. Diet and obstructive lung diseases. Epidemiol Rev 2001;23:26887.

6. Allan K, Kelly FJ, Devereux G. Antioxidants and allergic disease: a case of too little or too much? Clin Exp Allergy 2010;40:370-80.

7. Gilliland FD, Berhane KT, Li YF, et al. Children's lung function and antioxidant vitamin, fruit, juice, and vegetable intake. Am J Epidemiol 2003;158:576-84.

8. Harik-Khan RI, Muller DC, Wise RA. Serum vitamin levels and the risk of asthma in children. Am J Epidemiol 2004;159:351-7.

9. Kim JH, Ellwood PE, Asher MI. Diet and asthma: looking back, moving forward. Respir Res 2009;10:49.

10. Gao J, Gao X, Li W, et al. Observational studies on the effect of dietary antioxidants on asthma: a meta-analysis. Respirology 2008;13:528-36.

11. Baxter SD, Royer JA, Guinn $\mathrm{CH}$, et al. Origins of intrusions in children's dietary recalls: data from a validation study concerning retention interval and information from school food-service production records. Public Health Nutr 2009;12:1569-75.

12. Smith AF, Domel Baxter S, Hardin JW, Nichols MD. Conventional analyses of data from dietary validation studies may misestimate reporting accuracy: illustration from a study of the effect of interview modality on children's reporting accuracy. Public Health Nutr 2007;10:1247-56.

13. Ermakov IV, Ermakova MR, McClane RW, Gellermann W. Resonance Raman detection of carotenoid antioxidants in living human tissues. Opt Lett 2001;26:1179-81.

14. Hata TR, Scholz TA, Ermakov IV, et al. Noninvasive raman spectroscopic detection of carotenoids in human skin. J Invest Dermatol 2000;115:441-8.

15. Peng YM, Peng YS, Lin Y, et al. Concentrations and plasma-tissue-diet relationships of carotenoids, retinoids, and tocopherols in humans. Nutr Cancer 1995;23:233-46.

16. Centers for Disease Control and Prevention. NHIS Asthma Questions 1979 - 1996. Available from: http:/www.cdc.gov/ asthma/ pdfs/NHISquestions.pdf.

17. Rerksuppaphol S, Rerksuppaphol L. Effect of fruit and vegetable intake on skin carotenoid detected by non-invasive Raman spectroscopy. J Med Assoc Thai 2006; 89:1206-12. 
18. Trakultivakorn M, Sangsupawanich P, Vichyanond $\mathrm{P}$. Time trends of the prevalence of asthma, rhinitis and eczema in Thai children-ISAAC (International Study of Asthma and Allergies in Childhood) Phase Three. J Asthma 2007;44:609-11.

19. Phankingthongkum S, Daengsuwan T, Visitsunthorn N, et al. How do Thai children and adolescents describe asthma symptoms? Pediatr Allergy Immunol 2002;13:119-24.

20. Mohangoo AD, de Koning HJ, Hafkamp-de Groen E, et al. A comparison of parentreported wheezing or shortness of breath among infants as assessed by questionnaire and physician-interview: The Generation R study. Pediatr Pulmonol 2010; 45:500-7.

21. Allan K, Devereux G. Diet and asthma: nutrition implications from prevention to treatment. J Am Diet Assoc 2011;111:25868.

22. Egger RJ, Hofhuis EH, Sukonthanyakorn B, et al. Food intake and socioeconomic status in children in northeast Thailand. Trop Geogr Med 1991;43:42-50.

23. Zidichouski JA, Mastaloudis A, Poole SJ, et al. Clinical validation of a noninvasive,
Raman spectroscopic method to assess carotenoid nutritional status in humans. J Am Coll Nutr 2009;28:687-93.

24. Pelta Fernandez R, De Miguel Diez J, Alvarez-Perea A, et al. Risk Factors for Asthma Onset Between the Ages of 12 and 40. Results of the FENASMA Study. Arch Bronconeumol 2011;47:425-6.

25. Gu ML, Zhao J. Mapping and localization of susceptible genes in asthma. Chin Med J 2011;124:132-43.

26. Chung HL. Asthma in childhood: a complex, heterogeneous disease. Korean J Pediatr 2011;54:1-5. 